\title{
Quantification of the Disturbances of Phosphate Series Using the Box-Counting Method on Geoelectrical Images (Sidi Chennane, Morocco)
}

\author{
Abderrahim Ayad (1), ${ }^{1}$ Mahacine Amrani, ${ }^{2}$ and Saad Bakkali ${ }^{1}$ \\ ${ }^{1}$ Earth Sciences Department, Faculty of Sciences and Techniques, Abdelmalek Essaâdi University, Morocco \\ ${ }^{2}$ Engineering Process Department, Faculty of Sciences and Techniques, Abdelmalek Essaâdi University, Morocco \\ Correspondence should be addressed to Abderrahim Ayad; ayadabderrahim0@gmail.com
}

Received 19 March 2019; Revised 20 April 2019; Accepted 21 April 2019; Published 22 May 2019

Academic Editor: Angelo De Santis

Copyright ( 2019 Abderrahim Ayad et al. This is an open access article distributed under the Creative Commons Attribution License, which permits unrestricted use, distribution, and reproduction in any medium, provided the original work is properly cited.

\begin{abstract}
The phosphate series of Sidi Chennane (Morocco) is frequently affected by sterile bodies called "disturbances" causing many problems during the mining operation. The quantification of these bodies is thus considered as a crucial step for the OCP mining engineers. In following this research, we propose the fractal dimension as a new and simple efficient tool to analyze the disturbed areas. The work was carried out on geoelectrical maps of a study area of 50 hectares located in the northern part of the Sidi Chennane deposit. Fractal dimension was used as a representative parameter for examining the disturbed areas by using the box-counting method. The end result shows a strong linkage between the rate of the disturbances and the corresponding fractal dimension. This may have an important implication to quantify the disturbances and get a precise phosphate reserves estimate.
\end{abstract}

\section{Introduction}

Morocco holds more than $75 \%$ of the global phosphate reserves with more than 35 billion cubic meters. It is the world's leading exporter and the third largest producer after the USA and China with an annual output of 19 million tons. These appreciable reserves of phosphate were deposited in several basins, from northeast to southwest of Morocco (Ouled Abdoun, Gantour, Meskala, and Boukraa) and have been explored by L'Office Chérifien des Phosphates (OCP) since the 1920s [1].

In this study, we focused on Sidi Chennane mine which is one of the most important phosphate deposits in Ouled Abdoun sedimentary basin [2], located near the city of Khouribga, and at about $100 \mathrm{~km}$ in the southeast of Casablanca (Figure 1).

The phosphate series of Sidi Chennane frequently contains many sterile bodies of extremely locally high density called disturbances as a waste rocky material that must be removed (Figure 2).
These bodies are characterized by an irregular geometrical shape and dispersed without any order or privileged direction under a Quaternary cover. The geological investigations carried out in Sidi Chennane deposit have revealed that the origin of these structures is linked to the dissolution of the Senonian gypsiferous layers situated at the base of the phosphate series [3]. Their detection and delimitation required in many cases several exploration works, such as drilling wells that remain not particularly effective and increase drastically the cost of phosphate extraction. In light of this issue, the OCP Group has implemented with some Moroccan universities the geophysical mapping methods that underline the contrast of density between the disturbances and normal phosphate layers $[4,5]$. This had an important implication to delineate the disturbed areas in order to get a precise phosphate reserves estimate.

In the exploration and the estimation of the phosphate reserve, we need to know the local surface of the disturbances. The OCP Group engineers usually use classical approaches including geostatistical and geometrical methods. The 


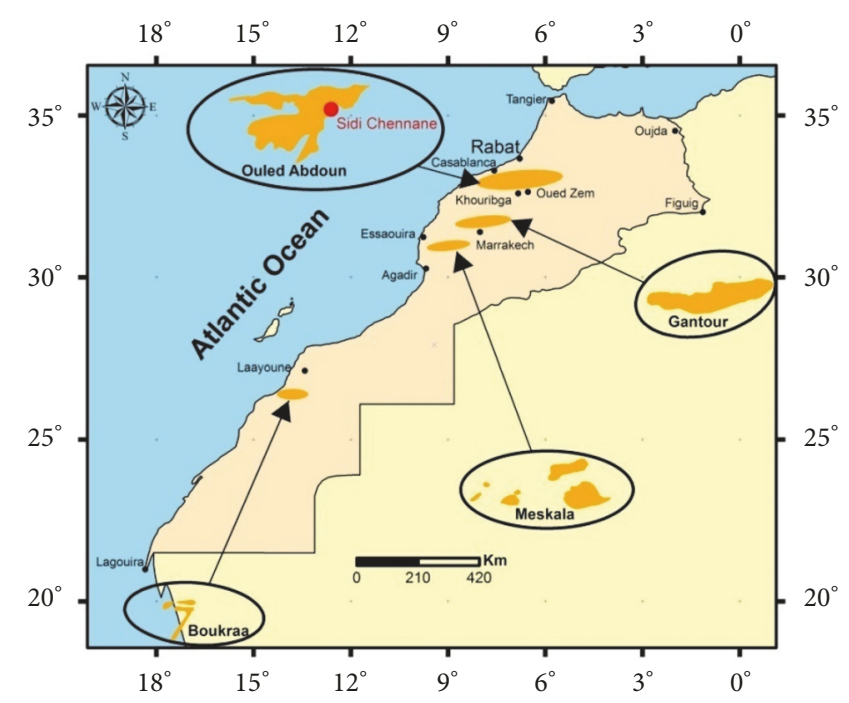

FIGURE 1: Main Moroccan phosphate basins. Sidi Chennane deposit location is highlighted with red color in Ouled Abdoun basin.

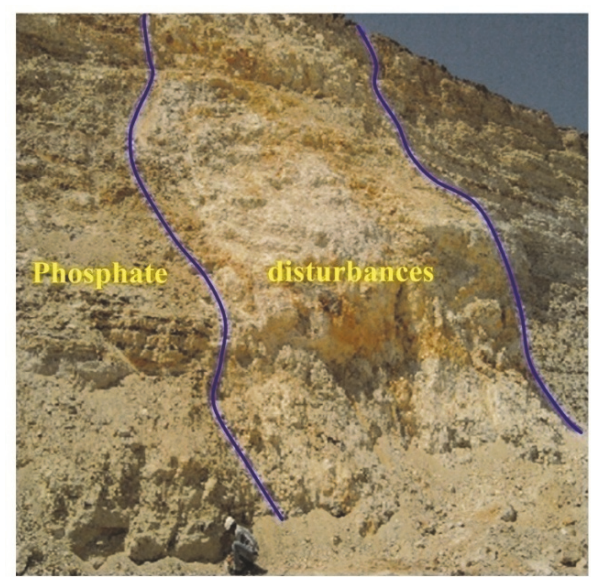

FIGURE 2: Geological sections showing disturbed phosphate series in Sidi Chennane quarry.

disturbed areas are partitioned according to the exploration plan and the phosphate reserves will be thus estimated through a discrete and linear function. Using these classical geometric methods, the irregular surface of the disturbances is only roughly estimated. The same surface measured at different scales will give different results.

In the last two decades, fractal geometry gained large popularity essentially in geosciences, where the measures to describe the forms of surfaces are essential. It was applied extensively in many studies and applications like rocks texture analysis [6], natural fractures pattern recognition [7], porous media [8-11], and naturally fractured reservoirs [12-14]. Throughout the present work, we have tried to point out that fractal geometry seems promising and more appropriate to quantify the disturbed areas since they commonly show an irregular geometry on the geoelectrical maps [15].

To achieve the goal of this paper, we present and discuss a case study carried out on an area of 50 hectares located in
Sidi Chennane deposit. The applicability and the relevance of fractal geometry in this study are verified from the variability of the geometrical aspect of the disturbances on the geoelectrical maps. This study aims to provide quantitative and useful means to quantify the disturbances and understand how going back fractal geometry may help in the phosphate reserve estimation.

1.1. Fractal Geometry Background. The fractals were coined by Benoit Mandelbrot in 1974 [16]. The term "fractal" starts from the Latin root "fractus" perfect passive participle of "frang" which means an irregular structure created following stochastic or deterministic rules. The fractal geometry is used to describe objects of complex shape that are practically impossible to be evaluated by conventional methods based on Euclidean geometry. Mandelbrot began his treatise on fractal geometry by explaining that a wide variety of natural objects does not conform to Euclidean geometry, "a mountain is not a cone, a coastline is not a circle, and clouds are not 


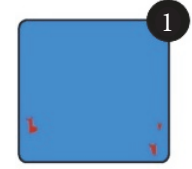

$\mathrm{FD}<1.00$

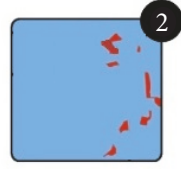

$1.00<\mathrm{FD}<1.26$

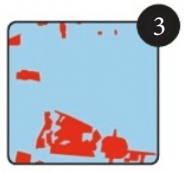

$1.26<\mathrm{FD}<1.54$

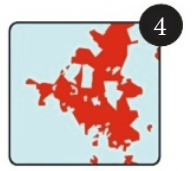

$1.54<\mathrm{FD}<1.78$

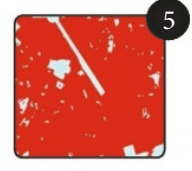

$1.78<\mathrm{FD}<2.00$

FIGURE 3: Variation of the fractal dimension FD as a function of the space filling level [18].

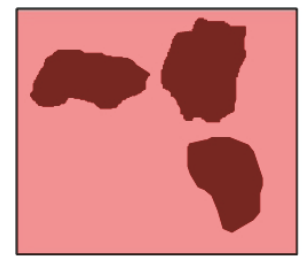

$\mathrm{r}=1, \mathrm{~N}(\mathrm{r})=1$

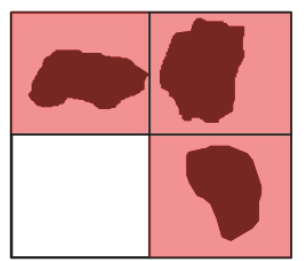

$\mathrm{r}=1 / 2, \mathrm{~N}(\mathrm{r})=3$

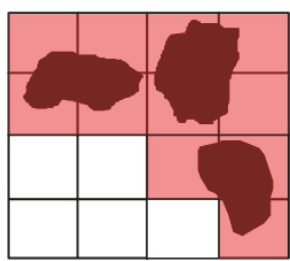

$\mathrm{r}=1 / 4, \mathrm{~N}(\mathrm{r})=11$

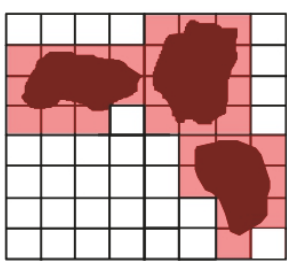

$r=1 / 8, N(r)=32$

FIGURE 4: Illustration of an irregular object in a box-counting test.

spheres"[17]. For example, if we ask "How long is the coast of Britain?" the answer to this question depends on how the measuring stick length is. As we let the length of the stick get small, the length of the coast becomes infinite, because the surface of the coast shows increasing detail the closer we zoom into it. A fractal is thus an object which consists of distinctive elements generated by the process of repeating the same operation for retaining the same pattern at different scales of examination. This is the central concept of fractal geometry summarized in the notion "self-similarity."

Over the years, fractal analysis becomes well known as a valuable tool for a quantitative measure of surface roughness. It is introduced as being complementary to solve the complex character of objects whose shapes show an irregularity. The main attraction of this approach stems from its ability to offer an appropriate way to quantitatively analyze data in a variety of fields, such as economics, physics, earth sciences, biology, chemistry, and other disciplines $[19,20]$. In contrast to Euclidian geometry measurement, fractal geometry is a relative way that allows obtaining the dimension of a very rough or bumpy area, length, or volume. In the Euclidian geometry, each set of elementary geometry has an integer dimension that equals 1 for straight line, 2 for square or circle, and 3 for the cube. This intuitive dimension is commonly known as Euclidean or topological dimension. However, fractal geometry allows the complex or irregular objects to be characterized in noninteger dimensions with values that may vary anywhere between 1 and 2 called fractal dimension FD. Figure 3 illustrates an excellent representation of the fractal dimension variation from 1 to 2D.

Moreover, many mathematical functions are considered space filling which maps a one-dimensional interval into a two-dimensional area such as Cantor set, Sierpiński curve, Dragon curve, and Peano curve [21-24]. These fractals are called mathematical fractals generated by exact iteration and do not have scaling limits.

\section{Materials and Methods}

Many methods for measurement fractal dimension can be used and the results obtained by different methods often differ significantly. Furthermore, not only the method but also the software used to calculate the fractal dimension may contribute to the differences. In this study, we obtained the fractal dimension by using the most popular method called the box-counting method. It is the well-known fractal method that is proposed by Russel [25]. It is an easier tool in the calculation process and more effective to deal with the irregularity. The typical approach of this method consists in covering the image to be measured with a grid of decreasing box size $\mathrm{r}$ and then counting the boxes elements that include some portion of the object N(r) (Figure 4).

The goal is to evaluate how the size of the box used to inspect pixels affects the number of boxes it takes to inspect all of the pixels. From one step to the next, as the size of the boxes shrink, the number of occupied boxes increases. Therefore, we obtain a set of data points that will be represented on a loglog Cartesian graph, which allows for identifying the fractal dimension value through a biasymptotic curve (named the empirical curve). For typical fractal object examined using the box-counting approach, the probability of a number of boxes $\mathrm{N}(\mathrm{r})$ includes some portion of the figure that is defined following (1), with FD being the fractal dimension:

$$
\mathrm{N}=\mathrm{r}^{\mathrm{FD}}
$$

The number of boxes $(\mathrm{N})$ and box size $(\mathrm{r})$ are expressed as a power law. The fractal dimension will be thus defined as

$$
\mathrm{FD}=-\frac{\ln \mathrm{N}(\mathrm{r})}{\ln (\mathrm{r})}
$$




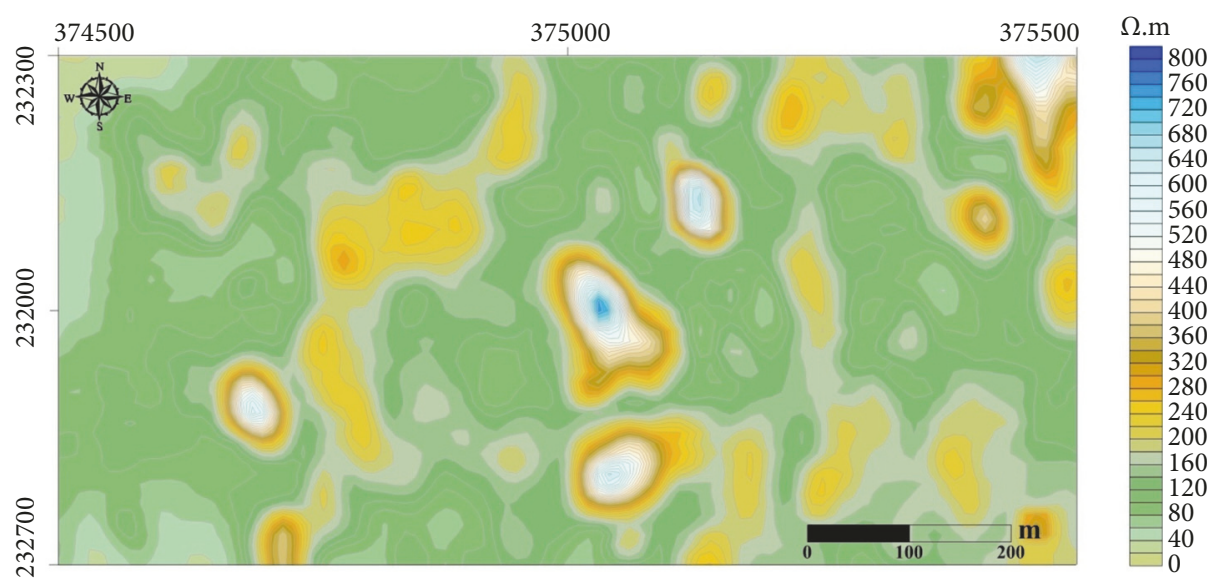

FIGURE 5: Apparent resistivity map of the study area.

where $r$ is the constant size of the box and $\mathrm{N}(\mathrm{r})$ is the number of boxes needed to completely cover the object in each measurement. The image is thus considered fractal when the relationship between the logarithms of $\mathrm{N}(\mathrm{r})$ versus the logarithms of $(r)$ is linear on a graph. This linearity indicates that a power law relates the number of boxes covering the object to their size.

In this work, the fractal analysis was performed on a set of 5000 apparent resistivity data acquired from a study area of 50 hectares within Sidi Chennane deposit $[26,27]$. The use of the geoelectrical method has its main aim in the detection of potential anomalies, and it is used in this work as an excellent parameter and a marker for distinguishing between disturbances and the phosphate rocks [28]. The geoelectrical anomalies are classified into phosphate rocks of a resistivity less than $200 \Omega$.m, and the disturbances that correspond to high values of apparent resistivity exceeded

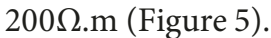

To get a complete characterization of the disturbed areas and provide accurate information, a set of fractal dimensions is needed, showing how the different disturbed areas have different fractal dimensions. For this aim, we start by constructing eight maps of apparent resistivity range from $200 \Omega$.m to $340 \Omega$.m using a cutoff frequency va.r of $20 \Omega$.m (Figure 6).

The box-counting analysis was carried on in this study by means of two separate programs HarFA 5.5 and fractalyse 2.4. Considering that using the combination of these two software programs would serve to cross-check and validate the results. These software programs were both used by researchers worldwide to approximate the complexity of objects, and they seem to be reliable as they have been validated in many studies $[29,30]$.

Before starting the analysis process, the geoelectrical maps have to be transformed into black and white binary images where the black pixels correspond to disturbances and white pixels correspond to phosphate rocks (Figure 8). The images were then transformed on bitmap format in order to be adapted to the fractal analysis software requirement.
Quantitative observations about geoelectrical images can be made to show a view of the geometric forms of disturbed areas. The edges extracted at different cutoff frequencies va.r allow observing to what extent the surface of the disturbance changes from one image to another. Then, for each image, the surface of the disturbances was explored by means of fractal dimension using the box-counting method.

Moreover, the precise estimation of the fractal dimension requires the choice of adequate size for the analyzed images. Because the image size is one of the most important parameters which impacts the results, changing the size may give different results for the same image. In light of this issue, the fractal dimension was firstly calculated for an image with full filling space (black image) without any irregularity or roughness, which corresponds generally to 2D. This is considered as an experimental basis for the irregular character of the disturbances. In order to obtain the correct result, we carried out several tests using different sizes and we have obtained different values of the fractal dimension. The chosen size corresponds to 510 pixels by 255 pixels which gave the best fit of fractal dimension, the closest to $2(1.9995$ by means of HarFA 5.5 with an error of \pm 0.0002 and 1.998 by means of fractalyse 2.4 with an error of \pm 0.0008 ) (Figure 7). Furthermore, as one can see the fractal analysis programs (HarFA 5.5 and fractalyse 2.4) gave slightly different results, which suggested that these software programs were operating correctly and were accurately characterized the fractality of the image submitted.

From this result, it is obvious that the fractal dimension $\mathrm{FD} \approx 2$ would correspond to an area without any disturbances. Meanwhile, this value will decrease and will be in the range of 1-2 according to the percentage of disturbances in which each one of the images is illustrated in Figure 7.

\section{Results and Discussion}

The validity of this study has been thus verified by applying the fractal analysis to images of different disturbed surfaces. Then, the number of boxes computed $\mathrm{N}(\mathrm{r})$ were plotted in a typical ln-ln graph (double logarithmic plots) versus their 


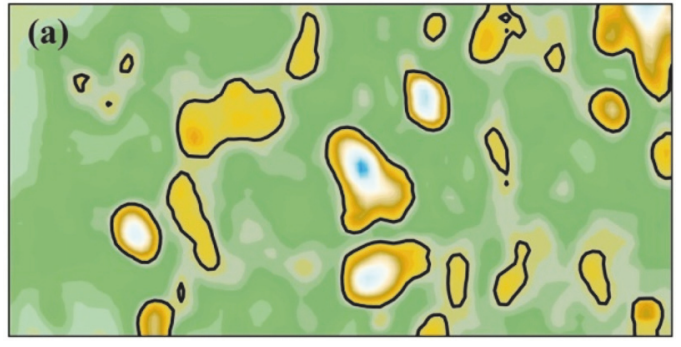

(a)

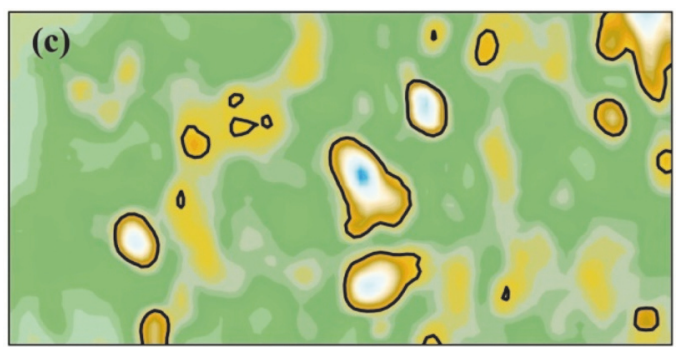

(c)

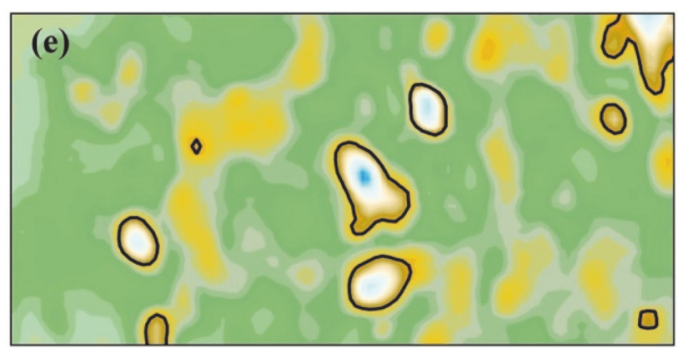

(e)

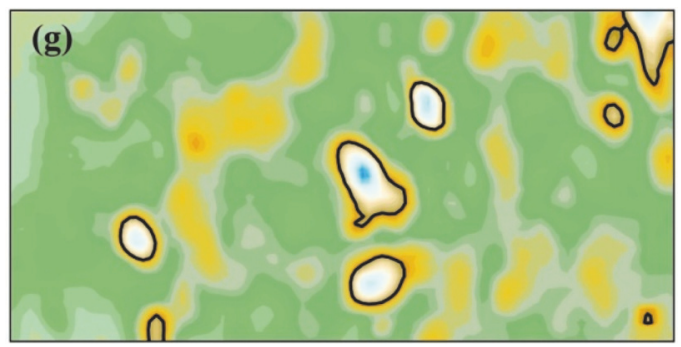

(g)

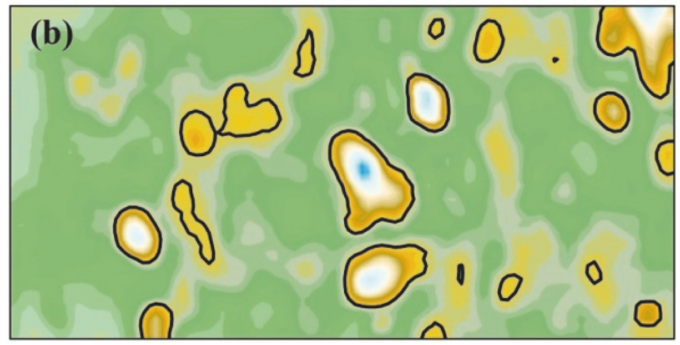

(b)

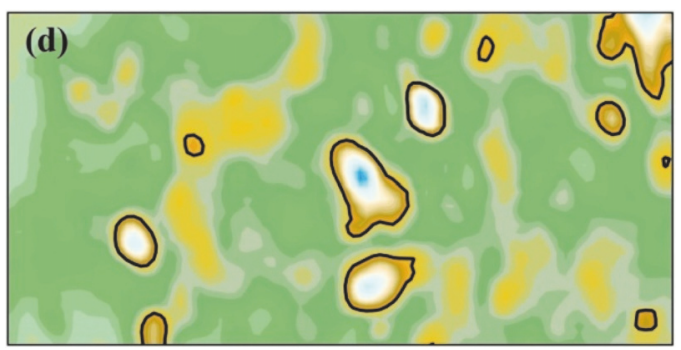

(d)

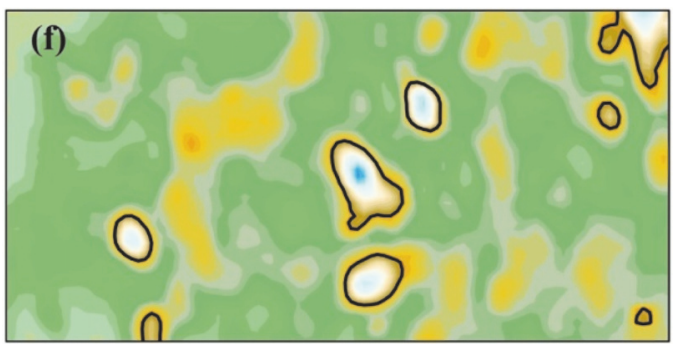

(f)

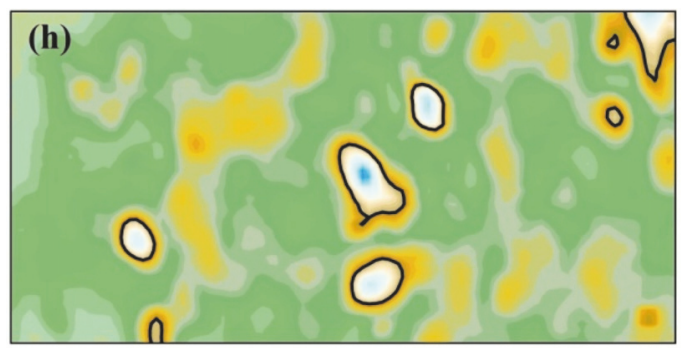

(h)

FIGURE 6: Comparative maps showing the geographical distribution pattern of apparent resistivity anomalies of disturbances across the study area. The cutoff frequencies $v_{\mathrm{a} . \mathrm{r}}$ used are, respectively, the following: (a) $v_{\mathrm{a} . \mathrm{r}}=200 \Omega$.m, (b) $v_{\mathrm{a} . \mathrm{r}}=220 \Omega . \mathrm{m},(\mathrm{c}) v_{\mathrm{a} . \mathrm{r}}=240 \Omega . \mathrm{m},(\mathrm{d}) v_{\mathrm{a} . \mathrm{r}}=260 \Omega$.m, (e) $v_{\text {a.r }}=280 \Omega . \mathrm{m}$, (f) $v_{\mathrm{a} . \mathrm{r}}=300 \Omega . \mathrm{m},(\mathrm{g}) \mathrm{v}_{\mathrm{a} . \mathrm{r}}=320 \Omega . \mathrm{m}$, and (h) $v_{\mathrm{a} . \mathrm{r}}=340 \Omega . \mathrm{m}$.

side length (r). The graphs are depicted in both Figures 9 and 10.

It is shown in Figures 9 and 10 that the fractal dimension computed exhibits a dependence between the logarithm of the number of boxes necessary to cover the disturbances and the logarithm of the box sizes. These plots prove different points, the most important of which is that the surface of the disturbances proves, in fact, to be fractal in a mathematical point of view. All the maps analyzed exhibited strong fractal properties, as one would note the linear character of the relationship between the logarithms of the number of occupied boxes and the box sizes highlighted by the high values of the correlation coefficients R2. Moreover, it is important to note that employing both two software programs in measurement added useful detail to cross-check and validate the results.

In this spatial analysis, it is interesting not only to characterize the morphology of the disturbances but also to help get an overall quantitative understanding of how the disturbed surface varies as a function of the fractal dimension. For this aim, it is important to systematically classify and compare between them. Firstly, the surface of 


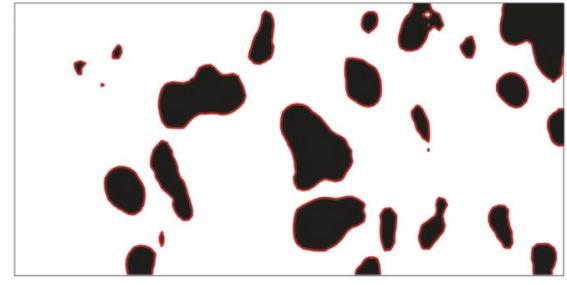

(a)

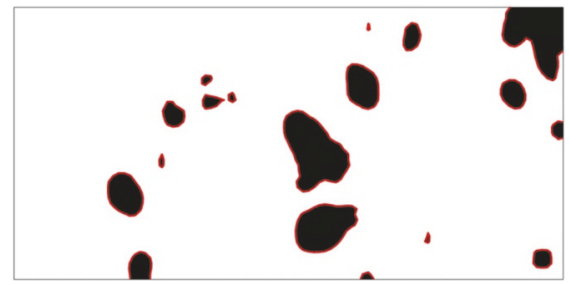

(c)

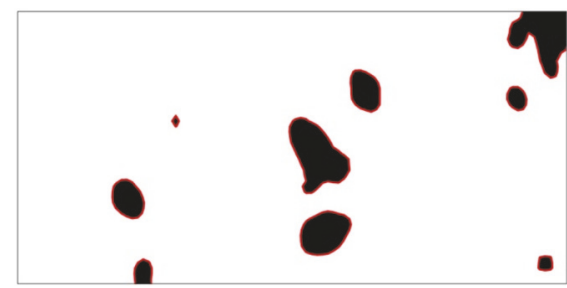

(e)

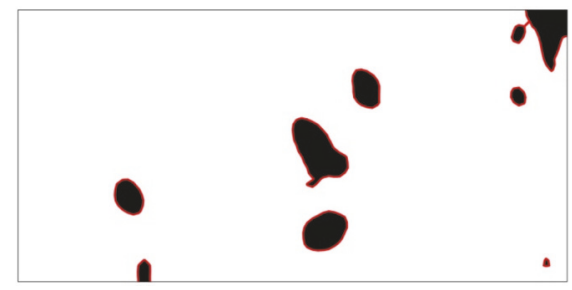

(g)

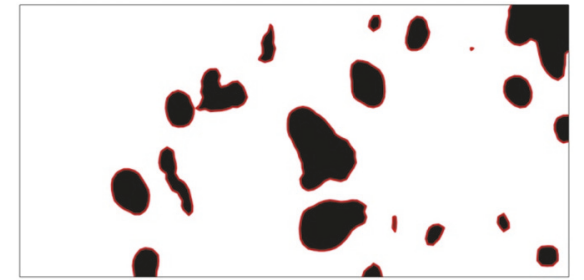

(b)

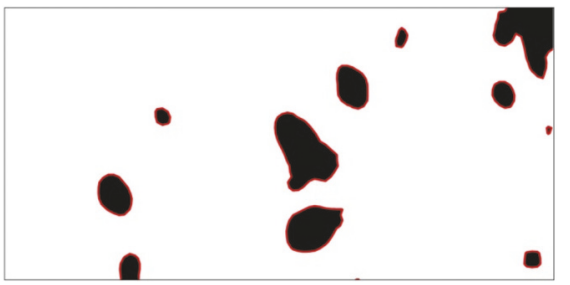

(d)

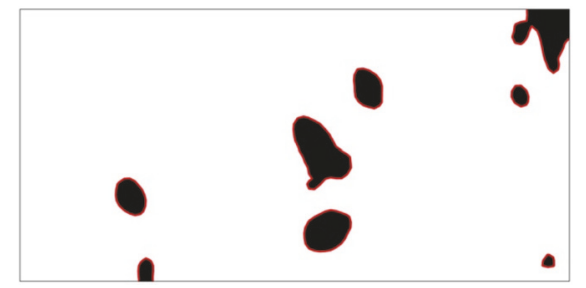

(f)

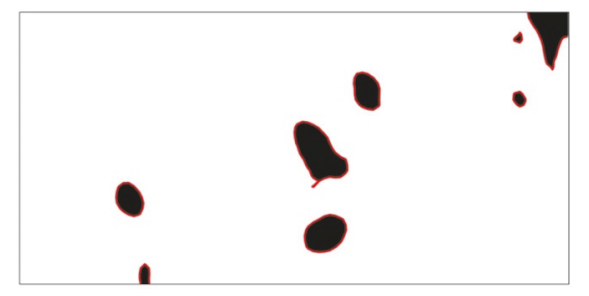

(h)

Figure 7: Black and white images of the maps displayed in Figure 6. The size of the images is 510 pixels by 255 pixels ( 381 Ko).

the disturbances was measured in each map using a Geographic Information System (GIS). Afterwards, the fractal dimensions calculated from both programs were significantly correlated with their rates of disturbances for showing a clear view of the analysis. The results obtained are summarized in Table 1.

From Table 1, it seems that the fractal dimension grows constantly with the increase of the surface of disturbances. The fractal dimensions calculated are in the range of 1.40-1.66 by means of HarFA 5.5 $\left(\mathrm{FD}_{\mathrm{HarFA}}\right)$ and in the range of 1.39-1.62 by means of fractalyse $2.4\left(\mathrm{FD}_{\text {fractalyse }}\right)$. For each one of the software programs, the FD values correspond, respectively, to the rates of disturbances range from $4.1 \%$ to $17.7 \%$. While this must emphasize that the fractal dimension using fractalyse 2.4 showed smaller values than the fractal dimension using HarFA 5.5, this divergence is more pronounced in maps having the highest disturbances rate.

It is apparent that there is an important statistical correlation that allows an expeditious comparison and thus may help in decision making as an index in phosphate exploration planning. The variation of fractal dimension values seems reasonable from viewing the different sampled images (Figure 7). It appears that the variation of FD values was really influenced by the spatial distribution of the disturbances and their shape into the overall area. This observation provides proof to support the process that a fractal dimension is a measure of space-filling capacity. As the space-filling rate is increased the fractal dimension is also increased and vice versa, indexing how the detail in disturbed areas changes. It reflects the relative amount of variation in the pattern, such that patterns with higher space-filling and thus higher visual complexity are quantified by higher FD values. Hence, the highest values of FD indicated that the disturbed areas are filling more space, resulting thus in a more shattered pattern. In contrast, the lowest fractal dimensions (FD) are typically associated with disturbed areas filling less space. This positive correlation indicates that the fractal dimension is an effective measure that proves this significance and seems 


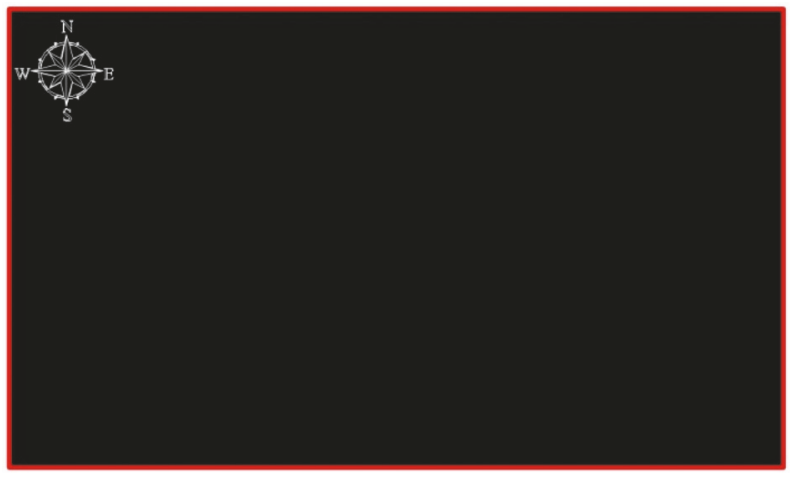

(a)

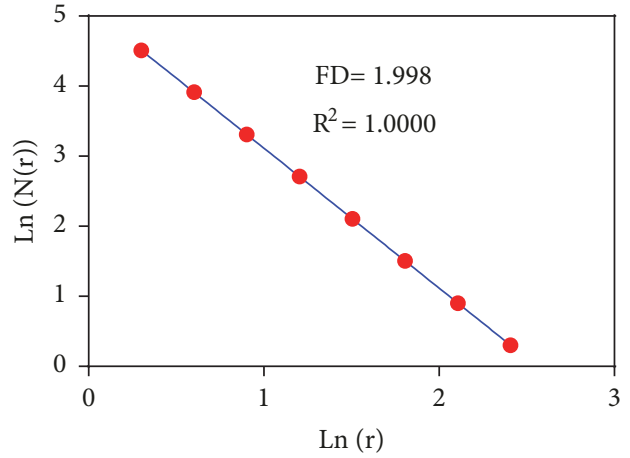

(A)

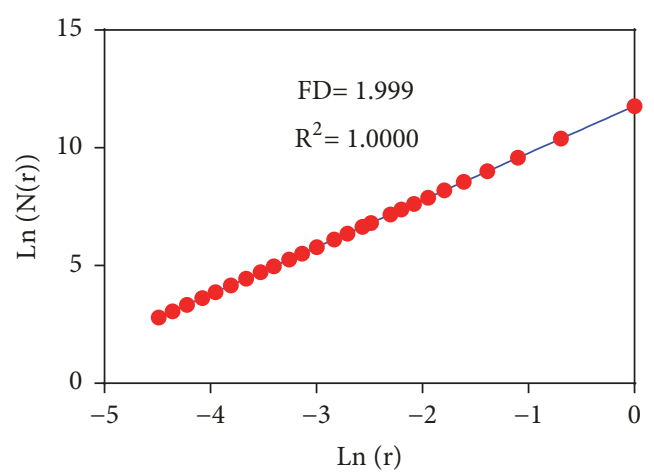

(B)

(b)

Figure 8: (a) 2D image with full filling space (black image). (b) Plot regression of the number of boxes N(r) against box side length (r) on logarithmic scales (A) using fractalyse 2.4 and (B) using HarFA 5.5.

to be most appropriate to quantify, compare, and evaluate the rate of the disturbances when applied to geoelectrical images.

The present study has improved the way of phosphate exploration planning through a comprehensive understanding of the spatial character of the disturbances. This is often a major concern in the Sidi Chennane area and other deposits around Ouled Abdoun basin. This analysis has described how much space is filled by disturbances in the area wherein they are embedded and therefore can help in the phosphate reserves estimation. Furthermore, the study is simple enough to be applicable to any phosphate deposits in Ouled Abdoun, as such opening a window of opportunity for the development of other automatic and quantitative tools to estimate the rate of the disturbances.

\section{Conclusions}

Throughout this work, we studied the fractal dimension utility to quantify the disturbances of the phosphate series on the geoelectrical maps. The box-counting method used to calculate the fractal dimension, and its performances were described. The article brings also the principle and the methodological frame of this method including formulas by which the fractal dimension was calculated.
Detailed examination of relations between disturbed areas and their corresponding fractal dimensions was achieved by means of two different software programs, HarFA 5.5 and fractalyse 2.4, which provides an interesting comparative and contextual framework for analysis. The end results suggested confirm the goodness for using the fractal dimension to examine the spatial patterns of the disturbances.

Since the OCP Group managers are eager for developing tools to quantify the impact of disturbances, the fractal analysis has met management needs since it produces results of practical significance. This framework of analysis may lead to an interesting assumption about using fractal geometry to get accurate phosphate reserve estimation and make the best exploration planning.

\section{Data Availability}

The data used to support the findings of this study are available from the corresponding author upon request.

\section{Conflicts of Interest}

The authors declare that there are no conflicts of interest regarding the publication of this work. 


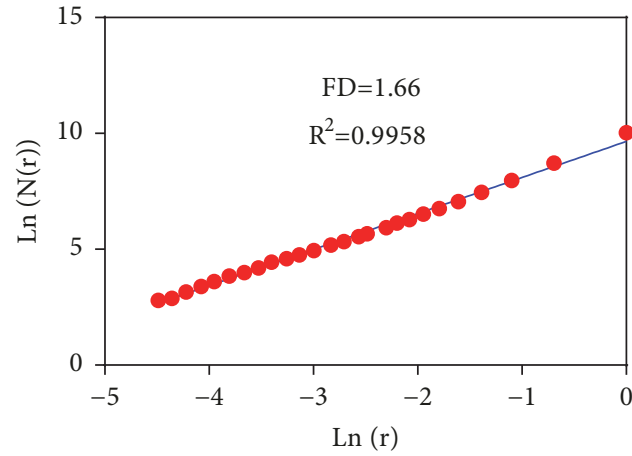

(a)

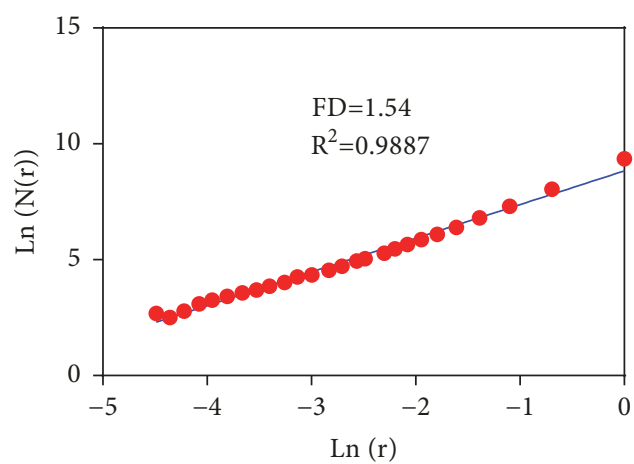

(c)

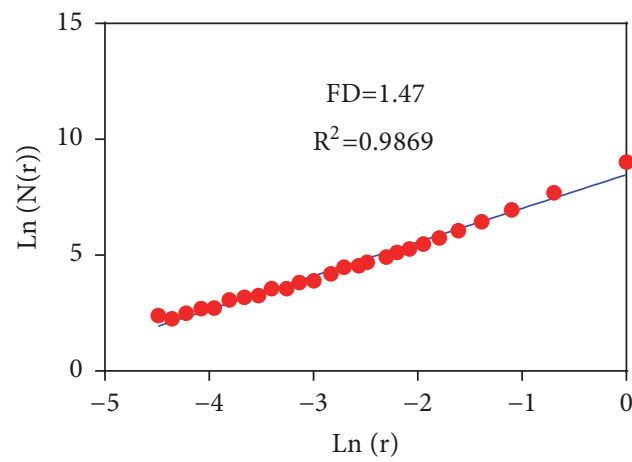

(e)

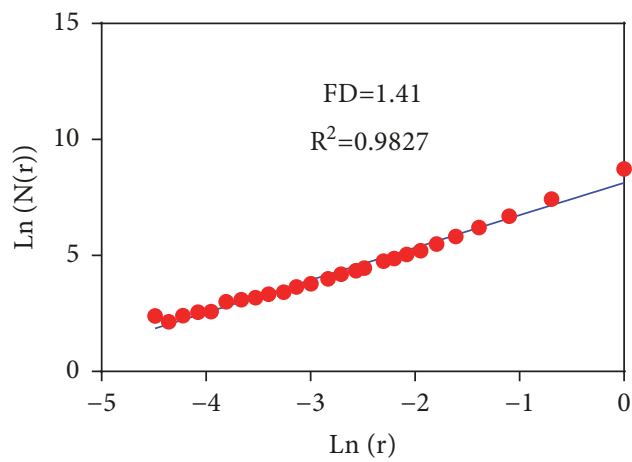

(g)

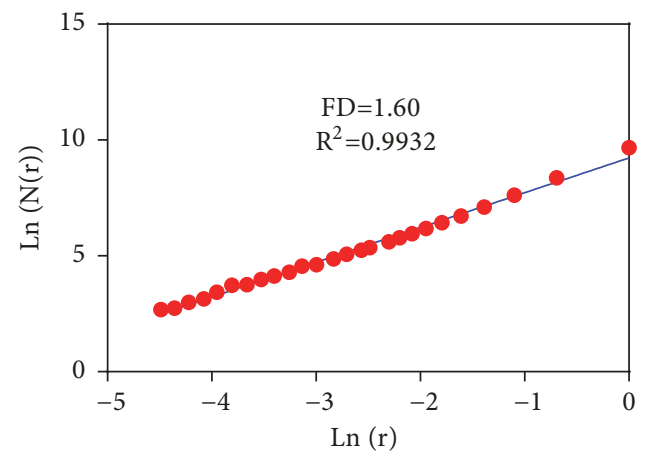

(b)

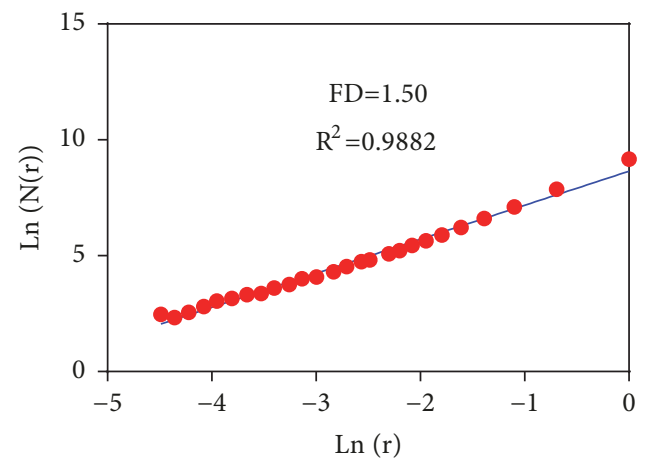

(d)

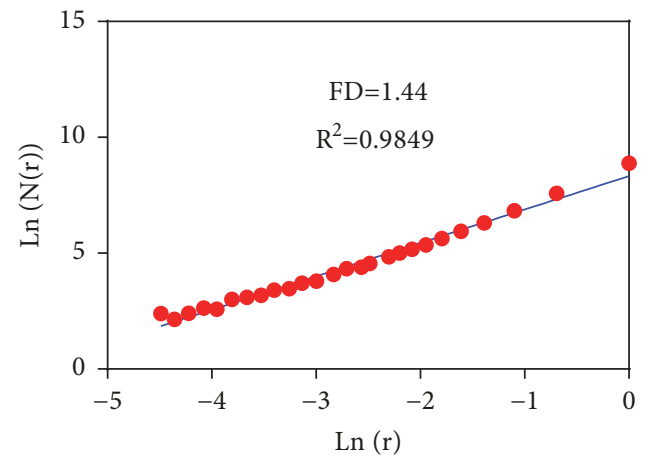

(f)

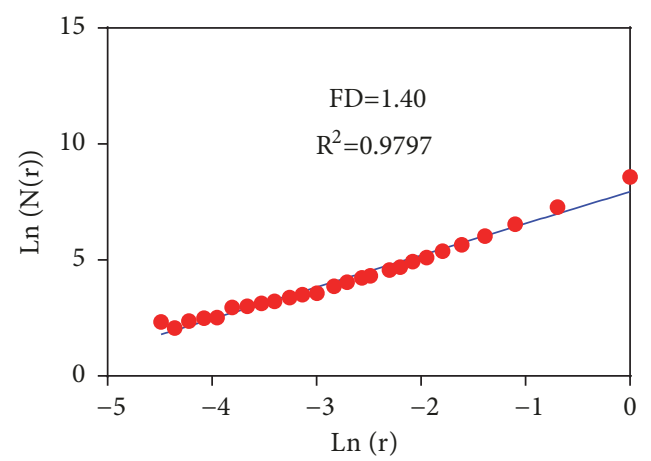

(h)

FIGURE 9: HarFA 5.5 plots showing the number of boxes $\mathrm{N}(\mathrm{r})$ against box side length (r) on logarithmic scales for each map in Figure 7. (a)

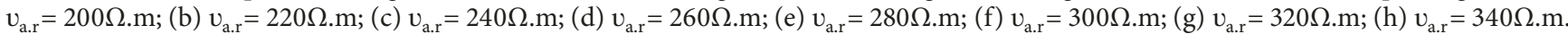




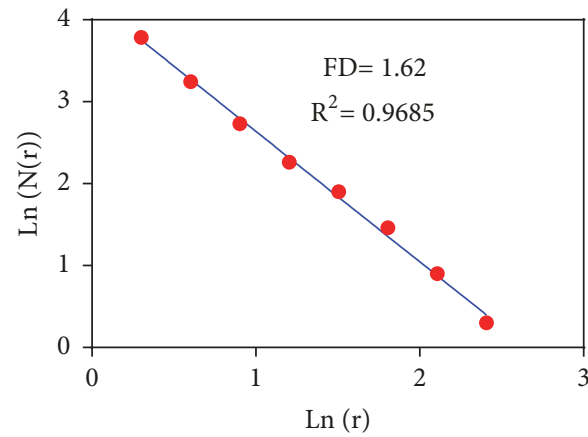

(a)

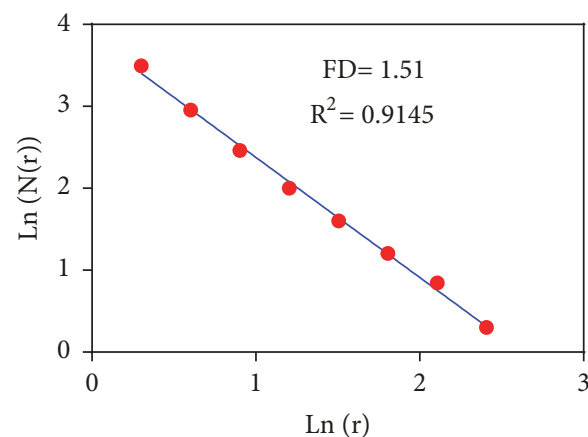

(c)

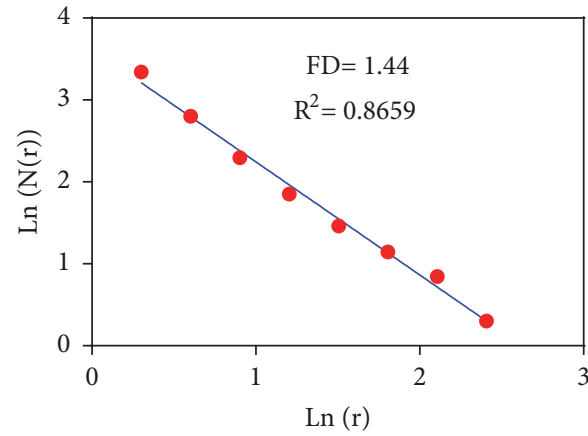

(e)

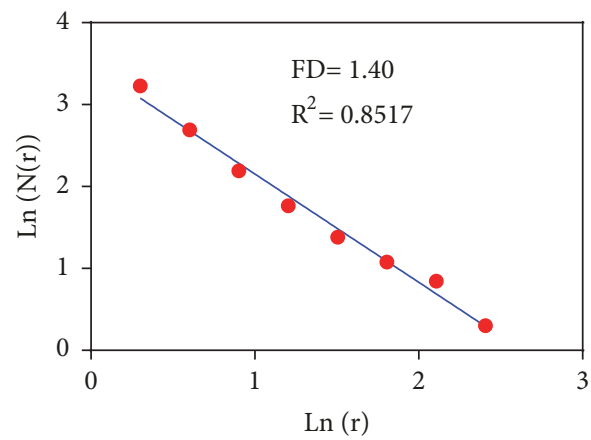

(g)

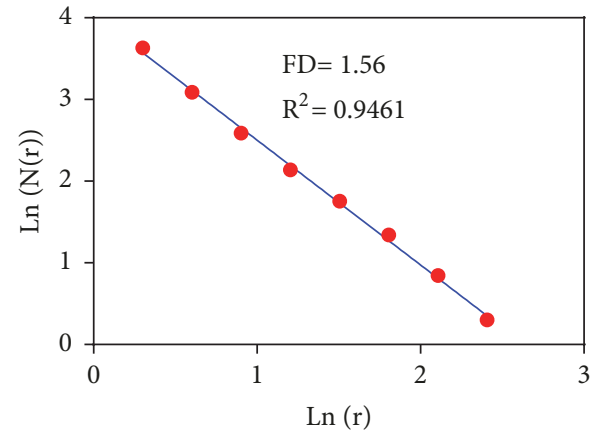

(b)

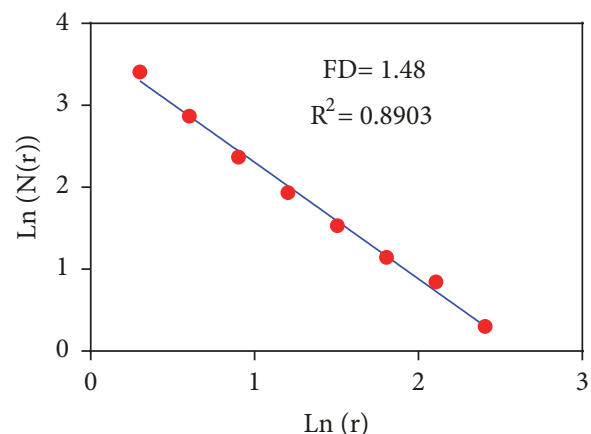

(d)

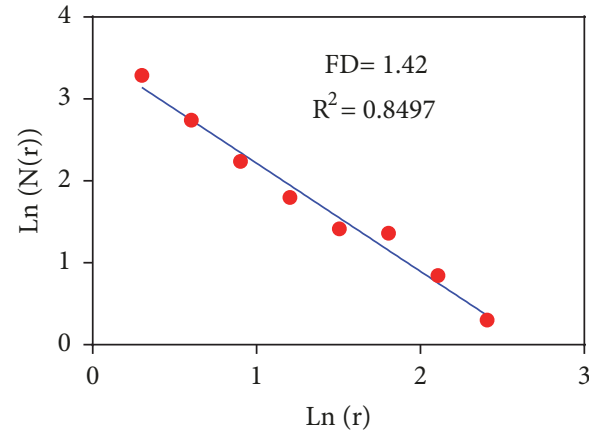

(f)

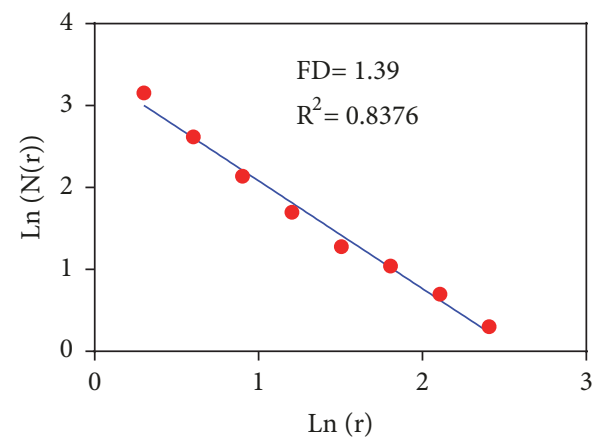

(h)

FIGURE 10: Fractalyse 2.4 plots showing the number of boxes $\mathrm{N}(\mathrm{r})$ against box side length (r) on logarithmic scales for each map in Figure 7. (a) $v_{a . r}=200 \Omega . m ;(b) v_{a . r}=220 \Omega . m ;$ (c) $v_{a . r}=240 \Omega . m ;$ (d) $v_{a . r}=260 \Omega . m ;(e) v_{a . r}=280 \Omega . m ;(f) v_{a . r}=300 \Omega . m ;(g) v_{a . r}=320 \Omega . m ;(h) v_{a . r}=340 \Omega . m$. 


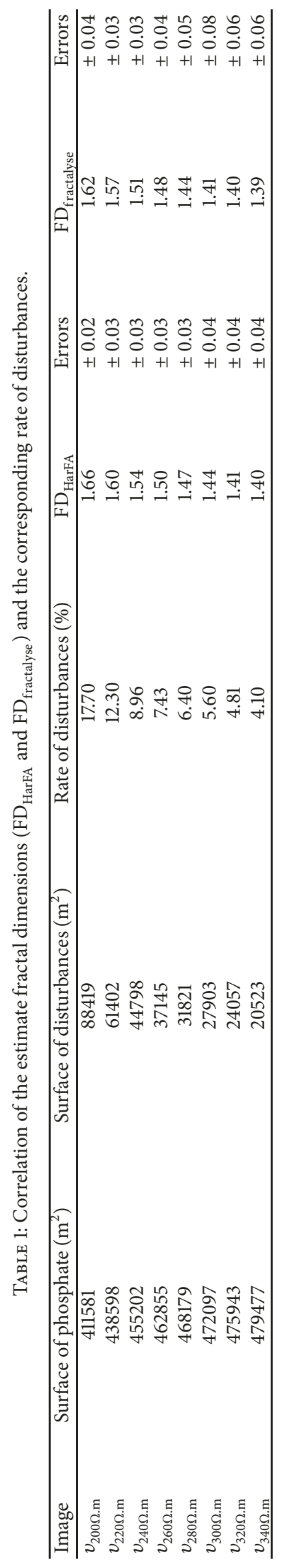




\section{Acknowledgments}

The authors thank the anonymous reviewers of the International Journal of Geophysics. This study was performed at the Environment, Oceanology, and Natural Resources Laboratory, Faculty of Sciences and Techniques of Tangiers, Morocco. The research is supported by a doctoral grant [UAE, L002/005, 2016] from the National Center for Scientific and Technical Research of Morocco (CNRST).

\section{References}

[1] M. Azmany, X. Farkhany, and H.-M. Salvan, "Gisement des ouled abdoun, géologie des gîtes minéraux marocains," Notes et Mémoires, Service Géologique du Maroc, vol. 276, no. 3, pp. 200-249, 1986.

[2] A. Ayad and S. Bakkali, "Interpretation of potential gravity anomalies of Ouled Abdoun phosphate basin (Central Morocco)," Journal of Materials and Environmental Science, vol. 8, no. 9, pp. 3391-3397, 2017.

[3] N. El Assel, A. Kchikach, C. Durlet et al., "Mise en évidence d'un Sénonien gypseux sous la série phosphatée du bassin des Ouled Abdoun: Un nouveau point de départ pour l'origine des zones dérangées dans les mines à ciel ouvert de Khouribga, Maroc," Estudios Geológicos, vol. 69, no. 1, pp. 47-70, 2013.

[4] A. Kchikach, M. Jaffal, T. Aïfa, and L. Bahi, "Cartographie de corps stériles sous couverture quaternaire par méthode de résistivités électriques dans le gisement phosphaté de Sidi Chennane (Maroc)," Comptes Rendus Geoscience, vol. 334, no. 6, pp. 379-386, 2002.

[5] N. E. Assel, A. Kchikach, T. Teixidó et al., "A ground penetrating radar and electrical resistivity tomography prospection for detecting sterile bodies in the phosphatic bearing of sidi chennane (Morocco)," International Journal of Geosciences, vol. 02, no. 04, pp. 406-413, 2011.

[6] A. Navarre-Sitchler and S. Brantley, "Basalt weathering across scales," Earth and Planetary Science Letters, vol. 261, no. 1-2, pp. 321-334, 2007.

[7] J. A. Leal, L. H. Ochoa, and J. A. García, "Identification of natural fractures using resistive image logs, fractal dimension and support vector machines," Ingeniería e Investigación, vol. 36, no. 3, pp. 125-132, 2016.

[8] B. M. Yu and P. Cheng, "A fractal permeability model for bidispersed porous media," International Journal of Heat and Mass Transfer, vol. 45, no. 14, pp. 2983-2993, 2002.

[9] I. Alfonso, A. Beltrán, M. Abatal et al., "fractal dimension determination of rock pores by multi-scale analysis of images obtained using om, sem and xct," Fractals, vol. 26, no. 05, pp. 1-26, 2018.

[10] Y. Xia, J. Cai, W. Wei, X. Hu, X. Wang, and X. Ge, "A new method for calculating fractal dimensions of porous media based on pore size distribution," Fractals, vol. 26, no. 1, Article ID 1850006, pp. 1-12, 2018.

[11] F. Wang, H. Li, D. Du, and X. Dong, "Investigation of dynamic texture and flow characteristics of foam transport in porous media based on fractal theory," Fractals, vol. 27, no. 1, pp. 1-12, 2019.

[12] L. Zhang, C. Cui, X. Ma, Z. Sun, F. Liu, and K. Zhang, "A fractal discrete fracture network model for history matching of naturally fractured reservoirs," Fractals. Complex Geometry,
Patterns, and Scaling in Nature and Society, vol. 27, no. 1, Article ID 1940008, 2019.

[13] L. Weifeng, Y. Guoliang, L. Yongdong, L. Xuefeng, D. Dongxing, and W. Rong, "Effect of fractal fractures on permeability in three-dimensional digital rocks," Fractals, vol. 27, no. 01, pp. 111, 2019 .

[14] W. Wei and Y. Xia, "Geometrical, fractal and hydraulic properties of fractured reservoirs: A mini-review," Advances in GeoEnergy Research, vol. 1, no. 1, pp. 31-38, 2017.

[15] A. Ayad and S. Bakkali, "Assessment of the geoelectrical anomalies of the disturbances of phosphate series using the triangular prism surface area method (sidi chennane -Morocco)," in Proceedings of the 2nd Conference on Geophysics for Mineral Exploration and Mining, Porto, Portugal, September 2018.

[16] B. B. Mandelbrot, "Stochastic models for the Earth's relief, the shape and the fractal dimension of the coastlines, and the number-area rule for islands," Proceedings of the National Acadamy of Sciences of the United States of America, vol. 72, no. 10, pp. 3825-3828, 1975.

[17] B. B. Mandelbrot, "How long is the coast of Britain? Statistical self-similarity and fractional dimension," Science, vol. 156, no. 3775, pp. 636-638, 1967.

[18] S. Encarnação, M. Gaudiano, F-C. Santos, -A. Tenedório, and J-M. Pacheco, "Fractal cartography of urban areas," Scientific Reports, vol. 2, no. 527, pp. 1-5, 2012.

[19] I. Gede Tunas, N. Anwar, and U. Lasminto, "Fractal characteristic analysis of watershed as variable of synthetic unit hydrograph model," The Open Civil Engineering Journal, vol. 10, pp. 706-718, 2016.

[20] Ç. Abidin and Ç. Ulus, "Three-dimensional modeling in medical image processing by using fractal geometry," Journal of Computers, vol. 12, no. 5, pp. 479-485, 2017.

[21] H. J. S. Smith, "On the integration of discontinuous functions," Proceedings of the London Mathematical Society, vol. 1-6, no. 1, pp. 140-153, 1874.

[22] G. Peano, "Sur une courbe, qui remplit toute une aire plane," Mathematische Annalen, vol. 36, no. 1, pp. 157-160, 1890.

[23] L. K. Platzman and I. Bartholdi III, "Spacefilling curves and the planar travelling salesman problem," Journal of the ACM, vol. 36, no. 4, pp. 719-737, 1989.

[24] S. Bailey, T. Kim, and R. S. Strichartz, "Inside the Levy dragon," The American Mathematical Monthly, vol. 109, no. 8, pp. 689703, 2002.

[25] D. A. Russell, J. D. Hanson, and E. Ott, "Dimension of strange attractors," Physical Review Letters, vol. 45, no. 14, pp. 1175-1178, 1980.

[26] S. Bakkali and L. Bahi, "Enhancement edges of sidi chennane phosphate deposit 'disturbances' using non-parametric regression analysis of resistivity data," Annals of the Faculty of Engineering Hunedoara, vol. 4, no. 3, pp. 135-140, 2006.

[27] S. Bakkali and M. Amrani, "Denoising resistivity phosphate "disturbances" using haar mother wavelet transform (Sidi Chennane, Morocco)," Earth Sciences Research Journal, vol. 12, no. 1, pp. 62-71, 2009.

[28] S. Bakkali, “Modelling phosphates 'disturbances' depth using analytical signal responses of geoelectrical resistivity data (Sidi Chennane, Morocco)," in Proceedings of the Symposium on the Application of Geophysics to Engineering and Environmental Problems, pp. 524-524, 2011. 
[29] I. Thomas, P. Frankhauser, and D. Badariotti, "Comparing the fractality of European urban neighbourhoods: Do national contexts matter?" Journal of Geographical Systems, vol. 14, no. 2, pp. 189-208, 2012.

[30] R. Ma, C. Gu, Y. Pu, and X. Ma, "Mining the urban sprawl pattern: A case study on Sunan, China," Sensors, vol. 8, no. 10, pp. 6371-6395, 2008. 

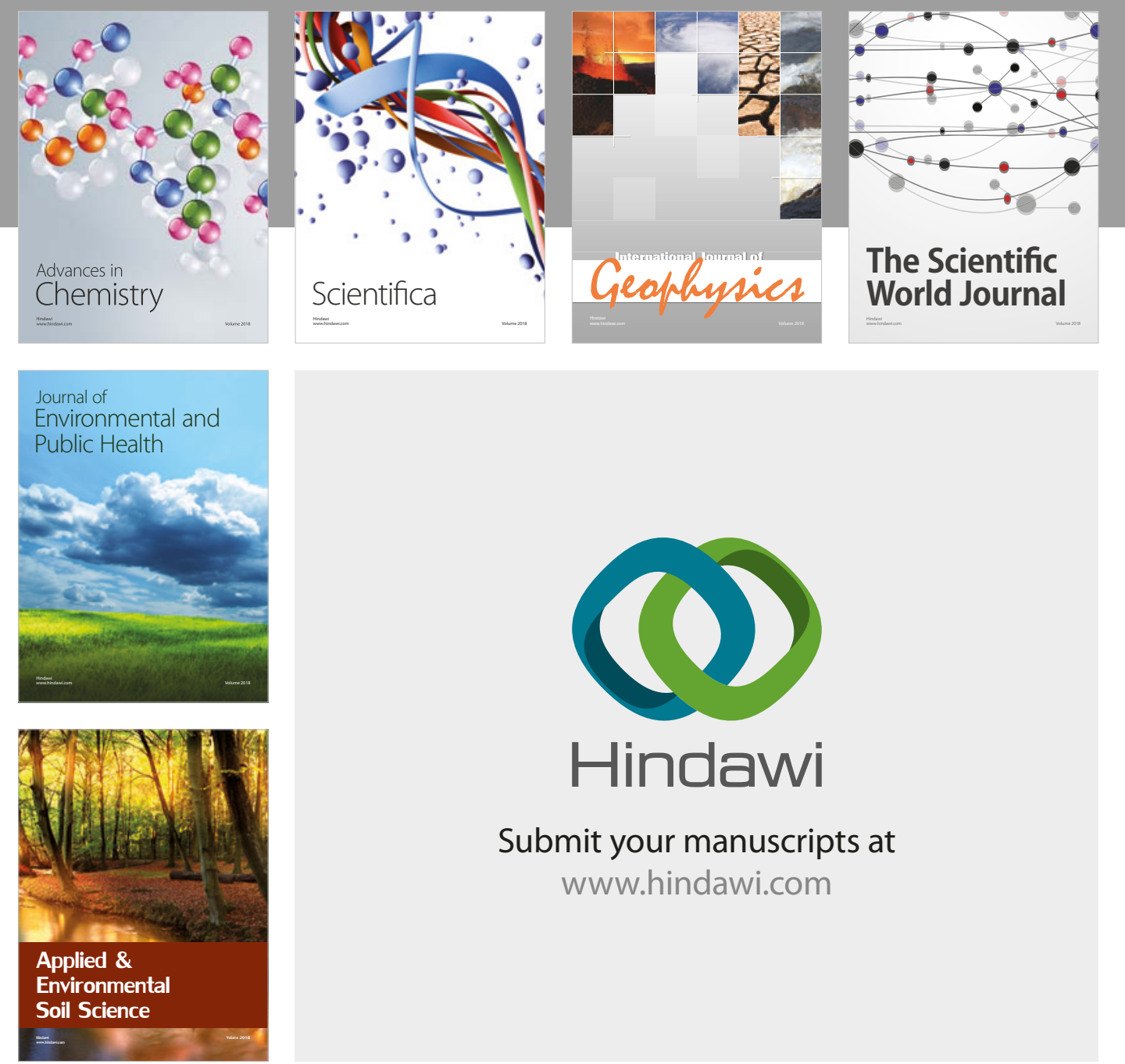

The Scientific

\section{World Journal}
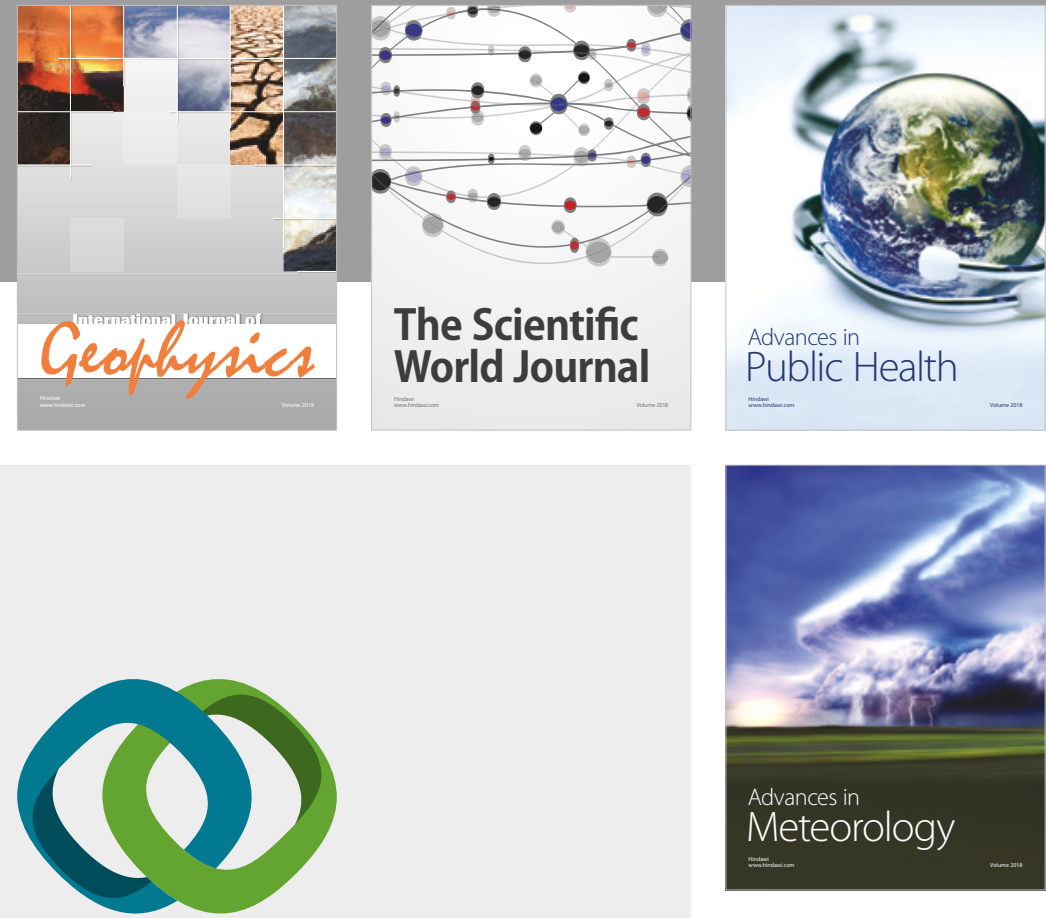

Advan

Public Health

\section{Hindawi}

Submit your manuscripts at

www.hindawi.com
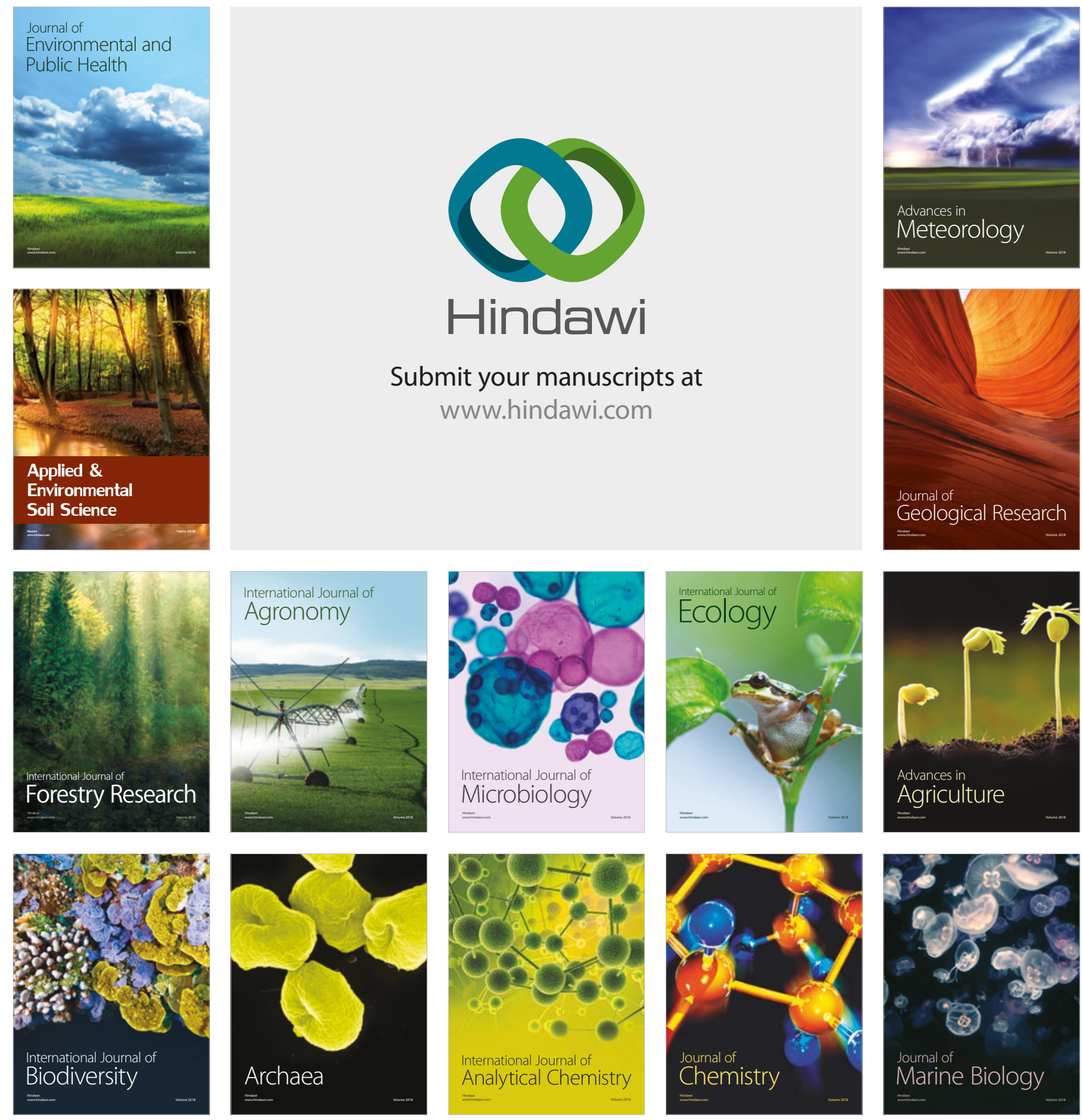